Vol. 2, No. 1, 2021

ISSN (ONLINE) 2597-0593

DOI 10.7146/njlis.v2i1.125220

(c) CC BY-NC-ND 4.0

Muhaimin Karim, Doctoral Candidate, Information Studies, Faculty of Social Sciences, Business and Economics, Åbo Akademi University, Finland, muhaimin.karim@abo.fi

Rajesh Singh, Associate Professor, Division of Library and Information Science, St. John's University, New York, USA, singhr1@stjohns.edu

Gunilla Widén, Professor, Information Studies, Faculty of Social Sciences, Business and Economics, Åbo Akademi University, Finland, gunilla.widen@abo.fi

\title{
Dealing with the COVID-19 infodemic
}

Understanding young people's emotions and coping mechanisms in Finland and the United States

\begin{abstract}
This exploratory study seeks to understand information experiences, emotional reactions, and coping mechanisms of young adults concerning the COVID-19 pandemic. Studying two different populations, the Finnish sample included 49 young adults, while the US sample included 154. A qualitative content analysis approach was utilized in analyzing research findings. Respondents experienced a variety of emotions including negative, positive, and neutral emotions while searching for information about the COVID-19 crisis. Respondents utilized limited information consumption, selective information consumption, and information avoidance as their primary coping mechanisms to manage information overload, anxiety, uncertainty, and emotional well-being. Overall, the findings highlighted similarities in young people's emotional reactions and coping mechanisms in managing the pandemic-related information in both countries. The study also revealed considerable differences in their perceptions about the role of media and politics in shaping how people consume and evaluate information.
\end{abstract}

Keywords: information overload, coping mechanisms, emotions, young people, media 


\section{Introduction}

It is clear that the outbreak of the COVID-19 pandemic has brought health information-related challenges in society to a new level of attention and concern; this phenomenon may even be called an infodemic, in which information from trusted authorities is presented side by side with misinformation and even disinformation (Dufva, 2020; Eysenbach, 2020; Ruokolainen \& Widén, 2019; Wardle \& Derakhshan, 2017), making it difficult to access reliable information about an issue (Xie et al., 2020). This kind of information overload is nothing new (Bawden et al., 1999; Eysenbach, 2006). Furthermore, it is widely recognized that information overload may lead to negative psychological and behavioral responses, activating coping mechanisms such as information avoidance, media refusal, selective scanning (Lee et al., 2019), and filtering or withdrawal strategy (Savolainen, 2007); information overload may also result in paradoxical consequences such as information poverty (Bawden \& Robinson, 2020), and lack of compliance with recommendations (Siebenhaar et al., 2020).

During global pandemics, vulnerable groups of the population, such as the young, can suffer disproportionately from the distress created by information overload, which affects their emotional well-being (Ahmed, 2020). The abundance of information about the COVID-19 pandemic across a wide range of communication channels-primarily online platforms, which young people consume (Boczkowski et al., 2017)-provides a strong rationale for investigating young people's emotional reactions to COVID-19 information overload. Moreover, this pandemic has created a unique situation for studying how different socio-cultural contexts manage with the same information challenge, referred to here as the COVID-19 infodemic. This study presents a comparative analysis between two diverse information environments, focusing on young adults in Finland and the United States; it aims to better understand their emotions and the coping mechanisms they use to navigate the complex information environment that has developed through the COVID-19 infodemic. The information and media landscape and consequently, information consumption practices, are substantially different in these two countries. Generally, American news channels are seen as less informative, but more competitive and commercialized, compared to mass media in European countries (Curran, 2012). This is especially true when American news outlets are contrasted with the mass media of Finland, where information is easily available for the public, indicating a more organized information environment than in the US (Curran, 2012; lyengar et al., 2010).

In the next sections, this study discusses previous research on information overload during global crises, the associated emotional reactions, as well as strategies people generally employ to process excessive amounts of information and cope with negative emotions triggered by information during global pandemics. Subsequently, the study's methods, materials, and findings are presented. Finally, the results are discussed in relation to previous research, contributing to a better understanding of how young people have experienced and navigated the COVID-19 infodemic; furthermore, through the comparative study between Finland and the US, the discussion section reveals how media and politics influence the ways in which people consume and evaluate information. These insights are valuable when planning information campaigns, health information policies, and information services for young people.

\section{Literature review}

\subsection{Information overload and emotional reactions in times of crisis}

The concept of information overload has been known for quite a while, and is usually defined as an occurrence when the amount of received information exceeds the one's ability to process it (Jacoby, 1977; Malhotra et al., 1982) and "information received becomes a hindrance rather than a help when the information is potentially useful" (Bawden et al., 1999, p. 250). Information overload can also be defined in relation to the quality of information, which is often associated with the uncertainty,

Karim, Singh and Widén: Dealing with the COVID-19 infodemic 
ambiguity, novelty, and complexity of information (Chae et al., 2016; Eppler \& Mengis, 2008; Schommer et al., 2001; Rachfall et al., 2015). People of all ages may suffer from information overload, but young people have experienced the most difficulty in processing large quantities of information (Bensilin \& Ragsdell, 2016; Edmunds \& Morris 2000). Schmitt et al. (2018) found that "the younger the participants were, the more they reported information overload in the context of online news exposure" (p. 1159). Young people are also the group with the most trust issues regarding quality of information (Benselin \& Ragsdell, 2016).

In times of crisis especially, people may feel inundated in an ocean of information and find it difficult to differentiate fact from fiction (Rachfall et al., 2015). This could result in feelings of distress, ambiguity, anxiety, frustration, as well as the inability to cope with such large amounts of information (Bawden et al., 1999; Kim et al., 2007; Klapp, 1986); alternatively, information overload could bring a sense of relief that there is so much information to sift through and learn from. There are a few studies that attempt to understand information behavior in times of crisis, focusing on students seeking information during the southeast Asian haze crisis (Pang, 2014), information needs during the Hurricane Sandy crisis (Lopatovska \& Smiley, 2014), and a study on the strategies for information dissemination to the community during a suspected tuberculosis outbreak (Duggan \& Banwell, 2004). However, none of these studies focused on understanding the role of emotions when people are exposed to an overwhelming amount of information in times of crisis.

Jin et al. (2010) have identified four negative emotions that are felt in times of crisis-anger, fright, anxiety, and sadness. These emotions can be triggered by different stimuli, including the thought of the crisis, the information spreading about the crisis, and the unknown that is to come. This negative emotional response to information overload can result in "psychological ill-being," in which an individual's well-being is negatively impacted due to the depression or anxiety that the information triggers (Swar et al., 2017). However, information overload can also positively impact well-being and cause someone to have positive emotions, such as satisfaction and relief. Some find value in increased amounts of information because they can feel at ease about conflicting pieces of information, find increased trust in information, and gain greater amounts of knowledge due to a plethora of information being available (Klausegger et al., 2007). Positive emotions can also exist in crisis. While people reported fear and anxiety following the 9/11 Terrorist Attacks in the United States, people used positive emotions-such as gratitude, interest, and love-and positive coping mechanisms to remain resilient through the hard times (Fredrickson et al., 2003). People either deal with information overload by continuing to seek more information or completely avoiding information, in favor of more positive and uplifting actions.

The negative consequences of information overload are apparent and trigger varying emotions and feelings in people thereby impacting their overall well-being. However, there is a limited understanding of how young adults manage their emotional health in times of crisis. Charles and Carstensen (2008) found in their study that younger adults are more emotional than older adults in unpleasant situations. While younger adults and older adults had equal levels of sadness in the study, younger adults were found to have higher levels of anger. They found that younger adults had higher levels of curiosity, wanting more information in unpleasant situations. This study seeks to understand how young adults processed their emotions and feelings during the COVID-19 pandemic when they were exposed to an unprecedented amount of pandemic-related information.

\subsection{Understanding emotional reactions}

While information overload is closely connected to emotional reactions, it is important to understand emotional well-being to be able to analyze coping mechanisms for information overload in a more holistic way. The notion of well-being is a multifaceted concept. Existing conceptualizations of well-

Karim, Singh and Widén: Dealing with the COVID-19 infodemic 
being consider the experience of happiness, a sense of purpose, wisdom, coherent philosophy of life, achievement, pleasure, and love as essential indicators of well-being (McMahan \& Estes, 2011). Similarly, information can significantly influence people's feelings, moods, and emotions. Thus, information can make people happy, angry, sad, panicked, or accomplished, in addition to impacting their overall well-being.

The Basic Emotions Theory (BET) provides a framework to understand emotions and feelings (Ekman et al., 1969). However, before delving deeper into BET, it is important to understand the difference between emotions and feelings. While these psychological concepts overlap, feelings are experienced consciously, whereas emotions manifest either consciously or unconsciously (Barrett et al., 2006). Barrett et al. (2006) also found that people have difficulty distinguishing between the meaning of the terms emotions and feelings, and this has created a unified understanding of the two terms in the minds of many. The act of feeling is often associated with expressing an emotion. As a result, due to the close resemblance between feelings and emotions, many people use both these terms interchangeably (Prinz, 2005). This prompted us to use both these terms interchangeably in order to develop a holistic understanding of emotional well-being of people.

Ekman et al. (1969) is credited with creating the Basic Emotions Theory (BET). BET provides a good basis to identify six major types of emotions-happiness, fear, disgust, anger, surprise, and sadness. Ekman et al. (1969) distinguished and determined these six major types of emotions by observing photographs of facial expressions of emotions from people of five different countries. Expanding on $B E T$, researchers and scholars have provided a number of theories and constructs to categorize emotions (Keltner et al., 2019; Plutchik, 1984; Tracy \& Robins, 2004). Most of these conceptualizations recognize fear, anger, sadness, happiness, surprise, and disgust as core, or primary, emotions. Some of these studies expanded on these categories, including more emotions, or advocated for the possibility of mixing of emotions. Scholars have also considered classifying these emotions into negative (e.g., fear, anger, disgust, sadness), positive (e.g., happiness, serenity, awe), and neutral (e.g., indifferent) emotions (Campos et al., 2013; Gasper et al., 2019). Campos et al. (2013) categorize the main eight positive emotions as amusement, awe, contentment, gratitude, interest, joy, love, and pride. Their research also highlights that negative emotions generally involve personal well-being, meanwhile positive emotions involve social functions and relationships (Campos et al., 2013). Negative emotions are unpleasant feelings that generally make someone feel badly about themselves or a situation they find themselves in. However, it has been found that positive and negative emotions can co-exist, because there is personal subjectivity in whether an action or information results in positive or negative emotions (An et al., 2017).

According to an estimate, 34,000 distinct emotions exist (Watkins, 2015). While it is difficult to recognize all 34,000 types of emotions, it would be useful to identify the major emotions and act accordingly. In a similar vein, attempts have also been made to create wheels of emotions in order to convey this vast array of emotions. While Plutchik (1984) created a wheel of emotions, Geoffrey Roberts created his own wheel of emotion that expanded each main, or primary, emotion into secondary and tertiary levels of emotions that correspond to the primary emotion (Yau, 2020).

\subsection{Information overload and coping strategies}

As stated earlier, during crisis situations, information can trigger a variety of emotional reactions. While the abundance of information can result in positive emotions such as sense of relief, information overload can also provoke negative emotional reactions, such as stress, fatigue, exhaustion, and even discontinuation of the use of information sources (Fu et al., 2020; Guo et al., 2020 ; Matthews et al., 2020). To avoid such negative emotions, and to protect their emotional wellbeing, people tend to use different coping mechanisms. These coping mechanisms are grouped in two

Karim, Singh and Widén: Dealing with the COVID-19 infodemic 
major types: problem-focused coping and emotion focused coping (Lazarus \& Folkman, 1984). The problem-focused approach involves taking control of the information load and involves activities to avoid stress and regulate information consumption. The emotion-focused approach, in contrast, is aimed at reducing or managing emotional distress through denial or avoidance. However, Boniwell and Tunariu (2019) recognized that people sometimes rely on both coping strategies to manage adversities.

Problem-focused coping strategies aim at adjusting the load of information in several ways. Savolainen (2007) found that individuals cope with excessive information by drawing on adjustment strategies such as queueing (delaying information uptake during peak load periods but hoping to catch up later) or filtering (leaving some types of information unprocessed, according to some scheme of priorities), or withdrawing (keeping the number of daily information sources at a minimum in order to shelter oneself from an excessive bombardment of information). Similarly, Pentina and Tarafdar (2014) suggested two more coping strategies that are used to determine the reliability of sources: "screening news stimuli" and "processing and interpreting news information". Screening news stimuli involves the information consumer determining the channels, sources, and content of news consumed. Processing and interpreting news information focuses on the socially mediated reliability of those channels, sources, and content. Pentina and Tarafdar (2014) further divide these strategies into two sub-strategies: 1) "load adjustment," which involves pruning, reducing, filtering; as well as 2) "effective processing," which involves sorting, ordering, and prioritizing.

In contrast, emotion-focused coping strategies aim to protect emotional well-being through discontinuation of information seeking or avoiding information when an individual encounters information overload. Sweeny et al. (2010) suggest that people tend to avoid information when new information may cause unpleasant emotions or diminish pleasant emotions. According to their information avoidance framework, individuals most commonly avoid information when learning the information is associated with aversive emotions (e.g., receiving a cancer diagnosis elicits fear) or requires individuals to take undesired actions (e.g., undergoing surgery) (Sweeny et al., 2010). Likewise, Karim et al. (2019) found that young people are likely to avoid information that might be expected to raise anxiety, embarrassment, or discomfort.

However, Song et al. (2021) showed that not only perceived threats but also information overload can trigger negative emotions such as sadness, anxiety, and cognitive dissonance which may eventually prompt coping mechanisms such as information avoidance. In a more recent study, Ahmed (2020) identified selective scanning, media refusal or resistance, and information avoidance as possible behavioral responses to information overload. Similarly, Soroya et al. (2021) found that information overload predicts information anxiety, which further resulted in information avoidance. From these perspectives, information avoidance can be seen as both a pragmatic strategy to manage information overload and an emotion-focused strategy to cope with negative emotions.

\subsection{Research questions}

The literature review of previous studies indicates that information overload-particularly during global crises - can potentially provoke emotional reactions. People of all ages suffer from information overload, but young people have often encountered the most difficulty in dealing with large quantities of novel information (Bensilin \& Ragsdell, 2016; Edmunds \& Morris, 2000) which is an inevitable challenge during pandemics. Both scarcity of information and abundance of information can instigate both positive and negative emotional reactions. However, the emotional reactions to information during crises periods may also be heavily influenced by the information environment, thus prompting our first two research questions: 
RQ1a: What emotions have young people in Finland and the US experienced while managing COVID-19 related information?

RQ1b: How do these emotional reactions differ between young people in Finland and in the US?

The previous studies suggest that during such global pandemics, young people encounter difficulties collecting and comprehending pandemic-related information due to the large amount of irrelevant information that is produced and the novelty of the pandemic related information. People follow various strategies to cope with the overload of information, the scarcity of authentic information, and the anxiety inflicted by the pandemic itself. Therefore, this research found it necessary to study how information can inflict negative emotions on young people and what mechanisms young people use in different information environments to cope with such information challenges and the associated emotional reactions, thereby prompting the last two questions:

RQ2a: What coping mechanisms have young people in Finland and the US used to manage the amount of COVID-19 information and related emotional reactions?

RQ2b: How do these coping mechanisms differ between young people in Finland and in the US?

\section{Method and material}

An online survey was launched in spring 2020, in Finland (15.3-15.5.2020) and in the U.S. (5.44.6.2020), to collect research data about information experiences and emotional reactions during the COVID-19 outbreak (Appendix 1) The surveys administered to respondents in each country were almost identical with the exception of questions regarding information sources about the pandemic.

The survey asked mostly open-ended questions to develop an understanding of the roles that information and emotion play during a crisis, as well as identify strategies for managing information and media consumption. Additionally, the survey also inquired about the information sources that people used to search for information about COVID-19, and sought to understand how they evaluated the reliability of this information. The rationale behind conducting a qualitative survey was to capture people's raw emotions as they unfolded during the pandemic.

\subsection{Data collection approach}

The survey was distributed through various listservs, social media outlets, and Facebook groups throughout both countries. The survey targeted a wide variety of people, regardless of background or geographical location; respondents included librarians, information professionals, archivists, lawyers, accountants, teachers, pastors, and students, among others. Additionally, an appeal was made to the survey participants to pass on the survey link onto others who may have been interested in responding. While the Finnish survey was distributed in three languages (Finnish, Swedish, and English), the US survey was only distributed in English.

The overall Finnish sample comprised of 261 participants within the age range of 20-79 years old. The US sample included 1979 participants representing various age groups ranging from 18-88 years old. However, the present study only focuses on understanding the information experiences of participants 18-29 years old from both countries.

\subsection{Analysis procedures}

A qualitative content analysis approach was utilized to identify the types of emotions triggered by information consumption during the pandemic, as reported by the survey respondents. This was accomplished by identifying and analyzing phrases (e.g., anxious, sad, mad, etc.) respondents used to express their feelings about the quantity of information they received about the novel coronavirus. We utilized the Basic Emotions Theory (BET) framework (Ekman et al., 1969), studies on neutral 
emotions (Gasper et al., 2019; van Hooft \& van Hooff, 2018), and Geoffery Roberts's wheel of emotions (Yau, 2020) to classify respondents' emotions into three major categories:

Negative emotions: fearful, angry, sad, bad, disgust

Positive emotions: satisfied, empowered, prepared, confident

Neutral emotions: indifferent

By following the above framework, we quantified the emotional reactions of participants by analyzing frequency of the phrases they used to express their emotions and feelings (e.g., angry, sad, anxious, etc.). Similarly, this study utilized a qualitative content analysis approach to identify major themes in frequently used coping mechanisms that the respondents adopted.

Two different researchers analyzed the research data in their respective countries. While efforts were made to have a consistent approach in analyzing research findings, the analysis ultimately differed due to the scope, context, and magnitude of research data from both countries. For instance, findings in the US were based on the analysis of only one question related to respondents' emotional reactions and coping mechanisms. In contrast, the Finnish findings took into consideration the participants' emotional reactions and coping mechanisms expressed throughout the survey. Additionally, ethical protocols and considerations in handling research data presented further constraints in adopting a uniform approach to analyzing research findings.

As stated earlier, the present study included 18-29 years old participants from both countries. A brief description of the sample characteristics and analysis procedures is given below.

\subsection{Sample characteristics}

The Finnish sample included 49 young people. Almost half of the respondents came from the major municipalities of Finland: Turku (39\%), Helsinki (10\%), and Vaasa (10\%). Almost half of the respondents (49\%) came from Southwest Finland (Turku and Helsinki) which is also the COVID-19 epicenter of the country. While $80 \%$ of the respondents belonged to the age-group of $23-29,18 \%$ were between 18 and 22 . The sample group was female dominant: $78 \%$ were female, $20 \%$ were male, and $2 \%$ chose not to disclose gender. Out of the 49 respondents, $16 \%$ were of foreign background, $35 \%$ were Finnish, and $49 \%$ were Swedish speaking Finnish individuals. Most of the respondents were either students $(51 \%)$ or employed $(41 \%)$ while only $4 \%$ were unemployed. The data shows $6 \%$ of the sample have confirmed that they belong in the risk group while $8 \%$ of the respondents know someone who has been diagnosed with COVID-19 in their close environment.

The US sample included 154 participants from various geographical regions including 31 states and Washington, D.C.; the majority of these respondents were from New York (17.5\%), Michigan (16.2\%), and California (9.7\%). Notably, New York was a COVID-19 hotspot at the time of data collection. While the majority of respondents (94\%) were between $23-29$ years old, a small number $(6 \%)$ fell into the 18-22 age range. Respondents were overwhelmingly female (87\%); males accounted for $11 \%$ of the sample, while $2 \%$ of participants identified either as LGBTQ+, or did not wish to disclose their gender. Findings indicate that a majority of respondents were either employed (89\%) and/or students (50.6\%). A relatively small number of respondents included people from self-employed, unemployed, homemaker, and veteran categories. The analysis reveals that $13 \%$ of respondents were either diagnosed with COVID-19 or knew someone in their immediate environment who received a positive diagnosis. Similarly, $13 \%$ of respondents indicated that they belonged to a group considered at high risk for severe COVID-19 infection. 


\section{Findings}

\subsection{Understanding emotional reactions}

In the Finnish data, the majority of respondents faced adversity while seeking relevant information about the pandemic, preventive measures, and current updates (Appendix 2). Navigating the current complex information environment was difficult with so much information that could have been either correct or misleading. While the Finnish respondents felt the need to stay updated with the latest developments, the vast amount of information (along with misinformation and fake news) that they had to process was beyond the capacity of most respondents. This predominantly resulted in negative feelings and the dilemma of whether to continue seeking information despite the overwhelming volume of information or to discontinue seeking information and accept the risk of missing out on important developments. Expressions used by the respondents to describe their negative feelings included bad $(n=29)$, fear and anxiety $(n=9)$, panic $(n=9)$, stress $(n=8)$, and uncertainty $(n=5)$. In addition, they also experienced disappointing emotions such as: annoyance and worries, exhaustion, tiredness, frustration and irritation, anger, and obsessive thinking. Negative feelings tended to be associated with information quality and information presentation from media and news channels. Respondents shared while there was a substantial amount of information, most of this information was either incorrect, or irrelevant; the same information was often circulated on multiple channels. This complex information environment and the overwhelming volume of information (and misinformation) made seeking information distressing for young people. A comparatively smaller group of respondents mentioned that there were excessive news telecasts-particularly the repetition of negative news - which triggered obsessive thinking, and at times, racism (when the virus was widely referred as a Chinese virus). On these occasions, respondents mostly held the media responsible for the quality and proper presentation of information. Since the information regarding the pandemic was novel and unique in nature, it might have been substantially difficult for the general public to comprehend this information. Despite the expected overload of information and the distress that this usually creates, in the Finnish data, it was observed that a few respondents perceived information overload as a positive phenomenon. The respondents argued that having too much information also facilitate easy and quick access to information. In particular, the respondents who perceived a higher self-efficacy in seeking and evaluating information from different channels and media did not consider the volume of information overwhelming but rather sufficient. Respondents who relied on critical thinking and had the ability to validate information from multiple sources were seemingly unperturbed.

The US respondents experienced a variety of emotions including negative, positive, and neutral emotions while searching for information about the COVID-19 crisis (Appendix 2). A majority of respondents $(66.9 \%)$ reported predominantly negative emotions while searching for information about the COVID-19 crisis. These negative emotions are "fearful," "angry," "sad," "bad," and "disgusted." Fearful emotions included feelings of anxiety, fear, edginess, nervousness, worry, shock, panic, etc. The respondents expressed their feelings by using phrases such as "overwhelmed," "overloaded," "anxious," "scared," "frightened," "edgy," "nervous," "worried," "shocked," and "panicked," among others. Findings demonstrate that over half of the respondents (55.2\%) felt fearful about the COVID-19 pandemic. In addition, a small number of respondents reported that they felt "cautious," "tense," and "confused." Many respondents reported information overload, information anxiety, information uncertainty, and information addiction as major problems about the COVID-19 related information. Angry emotions included feelings of frustration, irritation, agitation, provocation, madness, anger, etc. Findings indicate that some respondents (9\%) were angry with the information they received during the COVID-19 pandemic. Some of them (3.9\%) reflected on their anger towards government inaction and the politicization of pandemic-related information by politicians and scholars. A number of respondents (5.2\%) were angry with the news coverage they encountered during the pandemic. Sad emotions included feelings of sadness, resignation, isolation, or a

Karim, Singh and Widén: Dealing with the COVID-19 infodemic 
combination of these. Findings demonstrate that some respondents (13.6\%) felt sadness about the information they received during the COVID-19 pandemic. Overall, respondents appeared to be sad, upset, and disheartened in addition to experiencing a host of other feelings highlighted above. Bad emotions included feelings of crankiness, fatigue, lack of focus, and unhappiness as expressed by the respondents. Findings highlight that some respondents (10.4\%) felt bad about the quantity of information they encountered during the COVID-19 pandemic. They also indicated that it was challenging for them to express their feelings because they felt they were in a state of "limbo." Their comments suggest that the respondents may have been frustrated with the government's role in dealing with the COVID-19 pandemic, or suspicious about the information it provided. Overall, their statements seem to suggest that the respondents felt unfocused or experienced a negative impact on their well-being due to the staggering amount of information they received during the pandemic. A small number of respondents (3.9\%) expressed emotions of disgust, including feelings about the unreliability, unhelpfulness, and sickening nature of the quality of information they received about the novel coronavirus pandemic. Overall, respondents' comments indicate feelings reflecting lack of trust in the information received. Additionally, being faced with an overwhelming amount of unhelpful information contributed to increased fear and anxiety. Furthermore, the comments highlight a desire to receive helpful and factual information from a single source. Overall, negative emotions were prominent among respondents during the pandemic. In contrast, a small number of respondents (7.1\%) expressed positive emotions about the COVID-19 news they received, and reported feeling satisfied, empowered, prepared, confident, "calm" or "comfortable" to deal with the amount of information. Findings also highlight that a substantial proportion of respondents (22.1\%) did not have strong feelings-and a majority of them appeared to be neutral or indifferent-about the amount of information they received during the COVID-19 pandemic. Findings also indicate that about $24 \%$ of respondents experienced a combination of emotions highlighted above i.e., negative, positive, neutral.

Overall, findings highlight that the respondents experienced a variety of emotions including negative, positive, and neutral emotions when they were exposed to an overwhelming amount of the COVID19 related information. Furthermore, respondents felt troubled by the media's negative and sensational news coverage about the COVID-19 pandemic in both countries. However, the US respondents displayed distrust, anger, and frustration towards the quality of the pandemic related information they received from the government unlike Finnish respondents.

\subsection{Coping mechanisms}

Among the Finnish respondents, it was observed that the challenges of the information environment that existed because of the pandemic and the information overload that ensued fostered different types of coping mechanisms; these types of coping mechanisms were used both independently and simultaneously when processing excessive amounts of information about the novel coronavirus. The coping mechanisms that were seemingly popular among the respondents were filtering, selective scanning, and screening news stimuli which involve limiting the information channels one relied upon to two to three as well as avoiding other information channels (Appendix 3). Additionally, direct and deliberate avoidance was also observed. When the amount of information became overwhelming and obstructed finding necessary information, a number of Finnish respondents no longer sought information. A small group of respondents appreciated the scope of distraction during the pandemic. Concentrating on other activities that they could partake in from home, and other entertaining social media content such as memes, helped them cope with the overwhelming amount of information.

The US respondents frequently utilized three coping strategies to manage their emotional well-being: limited information consumption, selective information consumption, and information avoidance (Appendix 3). Findings indicate that limited information consumption is among the most preferred

Karim, Singh and Widén: Dealing with the COVID-19 infodemic 
coping mechanisms employed during the COVID-19 crisis. A substantial number of respondents (38.3\%) tried to manage their emotional well-being by restricting their information consumption from various news sources including newspapers, TV, cable news outlets, social media, etc. The respondents' comments indicate that they confronted multiple challenges caused by information overload and that these were exacerbated by the circulation of fake news and misinformation. Their comments also highlight anger and disappointment with the quality of the information provided by the federal government. Quite a few respondents (11\%) adopted selective information consumption as their coping mechanism by making conscious decisions to seek information from preferred news sources and outlets and limit the quantity of information consumption and the amount of time spent on information consumption per day. Findings also demonstrate that the smallest number of respondents (10.4\%) utilized willful information avoidance to manage information overload. Other reasons for this strategy were to avoid negative news media coverage or the circulation of misinformation about the pandemic, which these respondents found upsetting. These respondents chose to simply ignore or avoid information for the sake of their emotional well-being. Overall, the majority of respondents had not been diagnosed with COVID-19 or did not know others in their immediate environment who had tested positive for the disease. Their primary coping mechanisms included limited information consumption, selective information consumption, and information avoidance. Moreover, some used additional coping strategies (10.4\%) including exercise, hobbies, talking with friends and family, social media avoidance, taking medication, etc. Similar coping strategies were also utilized by respondents who were not at high risk for severe illness or COVID-19related complications. Findings also revealed that the respondents who were either diagnosed with COVID-19 or knew someone who tested positive also frequently utilized limited information consumption, selective information consumption, and information avoidance as important coping mechanisms. However, they were relatively less engaged in utilizing additional coping strategies such as exercise, hobbies, talking with friends and family, social media avoidance, taking medication, etc. Findings also highlight that a handful of respondents (4.5\%) clearly indicated their inability to cope during the COVID-19 pandemic.

Overall, findings highlight more similarities than differences in young people's coping mechanisms in both countries. While the respondents experienced similar information overload challenges in their respective countries, the US respondents expressed additional concerns about COVID-19 related fake news and misinformation, and the federal government's approach in managing the pandemic. Nonetheless, respondents utilized more or less similar coping strategies to manage their emotional well-being.

\section{Discussion and implications}

This study examines young people's self-perceptions about their emotional reactions (RQ1a) and coping mechanisms (RQ2a) in managing the COVID-19 pandemic related information in Finland and the US. The other goal was to understand if there were any similarities and differences in the emotional reactions and coping mechanisms of young people (RQ1b, RQ2b). Overall, the findings highlight similarities in young people's approaches to manage their emotional well-being. However, we found considerable variations in young people's perceptions of the roles of media and politics and their influence on the ways in which young people consume and evaluate the pandemic related information in both countries. Overall, the following themes emerged from the study findings: 1 ) emotional reactions and approaches for managing emotions in times of crisis, and 2) emotions about media coverage and politics.

\subsection{Emotional reactions and approaches for managing emotions in times of crisis}

People were unable to travel with their usual freedom for two months or more, from March through June 2020, and were often confined to home except to address fundamental necessities or engage in

Karim, Singh and Widén: Dealing with the COVID-19 infodemic 
exercise within the social distancing norms advised during the pandemic. As a result, people experienced a variety of emotions including negative, positive, and neutral emotions. The present study highlights that young people predominantly experienced negative emotions and feelings (e.g., fear, anger, sadness, bad, and disgust) during the pandemic, and felt anxiety, frustration, isolation, distraction, etc. (Bawden et al., 1999; Kim at al., 2007; Klapp, 1986). These emotions were triggered by an overwhelming amount of the pandemic-related information they received during confinement. At the same time, a small number of respondents also experienced positive emotions and felt calm, comfortable, or confident about the coronavirus information (Campos et al., 2013; Klausegger et al., 2007). Quite a few respondents reported they did not have any strong feelings or felt indifferent or neutral about the pandemic information (Gasper et al., 2019). While it remains unclear, an individual's personality may influence their information handling approach, thereby helping them remain calm, comfortable, or neutral about the pandemic. Many respondents also experienced a combination of emotions highlighted above i.e., negative, positive, and neutral. This finding is consistent with the results of prior studies where people reported to experience a host of emotions in crisis (Fredrickson et al., 2003; Jin et al., 2010; Klausegger et al., 2007).

This research demonstrates that the COVID-19 pandemic and the resulting infodemic contributed to the creation of a frightening and unmanageable information environment. Adding to this fear, constantly evolving information, misinformation, and fake news sowed further uncertainty, confusion, anxiety, frustration, and distraction. In times of uncertainty, people crave information in the same way they crave food. This was clearly reflected in respondents' constant desire to find accurate information about the pandemic in order to stay safe and healthy. With information so readily available, young people constantly checked various information sources in hope of finding answers or helpful information. Instead, prevailing uncertainty and competing narratives about the novel coronavirus contributed to the creation of more anxiety and fear (Chae at al., 2016; Eppler \& Mengis, 2008; Schommer et al., 2001; Rachfall et al., 2015; Swar et al., 2017). Furthermore, the quest to find accurate health information appears to reach addiction-like levels for some respondents in both countries.

While people were bombarded by new routines and advice of all kinds, especially those relating to physical and mental well-being, it may have been helpful to support the public with specific coping mechanisms as reflected in this research. Our research suggests that respondents frequently utilized limited information consumption, selective information consumption, and information avoidance as their primary coping mechanisms to manage information overload, anxiety, uncertainty, and emotional well-being (Goleman, et al., 2017; Soroya et al., 2021). These coping strategies could enable young people to have better control in managing their emotional and physical well-being if utilized in times of crisis.

\subsection{Emotions about media coverage and politics}

This research illustrates a variety of emotions young people experienced while confined at home during the COVID-19 pandemic. A majority of young people who participated in the study from both Finland and the United States were frightened and found themselves perplexed by the barrage of information they needed in order to stay healthy and safe. However, an interesting finding is that the Finnish and US young adults' emotions about media and politics differed significantly (Appendix 4). This research shows that young people were troubled by media's negative and sensational news coverage about the COVID-19 crisis. Additionally, politicians, commentators, pundits, and experts further exacerbated the COVID-19 infodemic problem, both wittingly and unwittingly (Dufva, 2020; Eysenbach, 2020; Ruokolainen \& Widén, 2019; Wardle \& Derakhshan, 2017). This "information asymmetry" resulted in young people receiving contradictory information from various media outlets about physical hygiene, social distancing, mask wearing, etc. (Li et al., 2020, p. 703). In particular,

Karim, Singh and Widén: Dealing with the COVID-19 infodemic 
partisan politics, police brutality, and racial discrimination compelled the US respondents to deal with additional stressors regarding social issues and "civil unrest" during the pandemic. As a result, a substantial number of US youth (31.2\%) relayed their anger and frustrations (Carstensen, 2008 ) at the federal government for its inaction in handling the pandemic and their distrust of any government information communications received from the Trump administration. In contrast, Finnish youth were found to be quite content with their current government, the role of the national leadership during the pandemic, and with the immediate measures different government agencies took in order to provide comprehensible and precise information to its citizens. They trusted the authorities and believed that the administration was doing everything in the public's best interest. Hence, they believed information provided by the government and trusted the measures that were taken. It is noteworthy that some Finnish respondents were also critical of the Trump administration for spreading contradictory information about the COVID-19 pandemic.

\section{Conclusions and limitations}

In spite of the extensive efforts undertaken to complete this study, several limitations could not be avoided. The qualitative nature of this study presents constraints in generalizing the findings of this study in understanding how young adults managed their emotions and coping mechanisms when they encountered the COVID-19 pandemic related information. Another limitation of this study is that all responses in the survey were based on respondents' self-reports, which may be biased. This was clearly reflected in respondents' perceptions about the role of media and politics and their influence on the ways in which they consumed and evaluated information in their respective countries. Nevertheless, the research findings suggest a few important lessons for those in positions of power during crises or disasters. The first is that media can play a critical role in disseminating useful information to the public; they are essential and may be the most important source of public information in the wake of a crisis. The second lesson is that media needs to be careful in handling, monitoring, and disseminating information about a crisis. Media reports tend to powerfully affect people's perceptions about a crisis and their overall well-being during its course. It would therefore be helpful to determine a conscious and unified media strategy for disseminating information. However, given the scope, breadth, and variety of news media outlets at the local, regional, and national level in countries such as Finland and the US, it may be challenging to determine a national media strategy for handling information in times of crisis.

Nonetheless, it is possible to identify national-level organizations that could serve as gatekeepers for distributing authoritative information during a crisis. These organizations can further coordinate with the media to relay this information to the public. Third, while this is a tall order, it would be helpful for experts, politicians, media commentators, journalists, and experts to exercise caution in vetting information before sharing it with the public. Finally, it would be helpful to determine and identify a cohesive national strategy to improve people's information consumption habits and practices, and to equip them with the skills necessary to glean truthful information from the many sources available in times of crisis. 


\section{References}

Ahmed, S. T. (2020). Managing News Overload (MNO): The COVID-19 Infodemic. Information, 11(8), 375.

An, S., Ji, L.-J., Marks, M., \& Zhang, Z. (2017). Two sides of emotion: Exploring positivity and negativity in six basic emotions across cultures. Frontiers in Psychology, 8.

https://doi.org/10.3389/fpsyg.2017.00610

Barrett, L. F., Mesquita, B., Ochsner, K. N., \& Gross, J. J. (2006). The experience of emotion. Annual Review of Psychology, 58(1), 373-403. https://doi.org/10.1146/annurev.psych.58.110405.085709

Bawden, D., \& Robinson, L. (2020). Information overload: An overview. In: Oxford Encyclopedia of Political Decision-Making. Oxford U.P.

Bawden, D., Holtham, C., \& Courtney, N. (1999, October). Perspectives on information overload. In Aslib proceedings New Information Perspectives, 51(8), 249-255

Benselin, J. C., \& Ragsdell, G. (2016). Information overload: The differences that age makes. Journal of Librarianship and Information Science, 48(3), 284-297.

Boczkowski, P., Mitchelstein, E., \& Matassi, M. (2017, January). Incidental news: how young people consume news on social media. In Proceedings of the 50th Hawaii International Conference on System Sciences.

Boniwell, I., \& Tunariu, A. D. (2019). Positive psychology: Theory, research and applications. Open University Press.

Campos, B., Shiota, M. N., Keltner, D., Gonzaga, G. C., \& Goetz, J. L. (2013). What is shared, what is different? Core relational themes and expressive displays of eight positive emotions. Cognition and Emotion, 27(1), 37-52. https://doi.org/10.1080/02699931.2012.683852

Carson, H. (1930, May). Pleasant and unpleasant feelings. Psychological Review, 37(3), 228-240 https://doi.org/10.1037/h0074761.

Chae, J., Lee, C. J., \& Jensen, J. D. (2016). Correlates of cancer information overload: focusing on individual ability and motivation. Health Communication, 31(5), 626-634.

Charles, S. T., \& Carstensen, L. L. (2008). Unpleasant situations elicit different emotional responses in younger and older adults. Psychology and Aging, 23(3), 495-504.

https://doi.org/10.1037/a0013284

Curran, J., Coen, S., Aalberg, T., \& Iyengar, S. (2012). News content, media consumption, and current affairs knowledge. In J. Curran \& C. Aalberg (Eds.), How media inform democracy: A comparative approach (1st ed., pp. 81-97). Routledge.

Dufva, M. (2020). Megatrendit 2020. SITRA.

Duggan, F., \& Banwell, L. (2004). Constructing a model of effective information dissemination in a crisis. Information Research, 9(3). http://informationr.net/ir/9-3/paper178.html

Edmunds, A., \& Morris, A. (2000). The problem of information overload in business organisations: A review of the literature. International Journal of Information Management, 20(1), 17-28. 
Ekman, P., Sorenson, E. R., \& Friesen, W. V. (1969). Pan-cultural elements in facial displays of emotion. Science, 164, 86-88.

Eppler M.J., \& Mengis J. (2008) The concept of information overload - A review of literature from organizationscience, accounting, marketing, MIS, and related disciplines (2004). In: Meckel M., Schmid B.F. (eds) Kommunikationsmanagement im Wandel. Gabler. https://doi.org/10.1080/01972240490507974

Eysenbach, G. (2006). Infodemiology: Tracking flu-related searches on the web for syndromic surveillance. AMIA 2006 Symposium Proceedings, 244-248.

Fredrickson, B. L., Tugade, M. M., Waugh, C. E., \& Larkin, G. R. (2003). What good are positive emotions in crisis? A prospective study of resilience and emotions following the terrorist attacks on the United States on September 11th, 2001. Journal of Personality and Social Psychology, 84(2), 365-376.

Fu, S., Li, H., Liu, Y., Pirkkalainen, H., \& Salo, M. (2020). Social media overload, exhaustion, and use discontinuance: Examining the effects of information overload, system feature overload, and social overload. Information Processing \& Management, 57(6).

https://doi.org/10.1016/j.ipm.2020.102307

Gasper, K., Spencer, L. A., \& Hu, D. (2019). Does neutral affect exist? How challenging three beliefs about neutral affect can advance affective research. Frontiers in Psychology, 10(2476). https://doi.org/10.3389/fpsyg.2019.02476.

Guo, Y., Lu, Z., Kuang, H., \& Wang, C. (2020). Information avoidance behavior on social network sites: Information irrelevance, overload, and the moderating role of time pressure. International Journal of Information Management, 52. https://doi.org/10.1016/j.ijinfomgt.2020.102067

Iyengar, S., Curran, J., Lund, A. B., Salovaara-Moring, I., Hahn, K. S., \& Coen, S. (2010). Cross-national versus individual-level differences in political information: A media systems perspective. Journal of Elections, Public Opinion and Parties, 20(3), 291-309.

Jacoby, J. (1977). Information load and decision quality: Some contested issues. Journal of Marketing Research, 14(4), 569-573.

Jin, Y., Pang, A., \& Cameron, G. (2010). The role of emotions in crisis responses: Inaugural test of the integrated crisis mapping (ICM) model. Corporate Communications: An International Journal, 15, 428-452. https://doi.org/10.1108/13563281011085529

Karim, M., Widén, G., \& Heinström, J. (2019). Influence of demographics and information literacy self-efficacy on information avoidance propensity among youth. In Proceedings of CoLIS, the Tenth International Conference on Conceptions of Library and Information Science, Ljubljana, Slovenia, June 16-19, 2019. Information Research, 24(4), http://InformationR.net/ir/24-4/colis/colis1909.html

Keltner, D., Sauter, D., Tracy, J., \& Cowen, A. (2019). Emotional expression: Advances in basic emotion theory. Journal of Nonverbal Behavior, 43(2), 133-160. https://doi.org/10.1007/s10919019-00293-3

Kim, K., Lustria, M. L. A., Burke, D., \& Kwon, N. (2007). Predictors of cancer information overload: Findings from a national survey. Information Research, 12(4), 12-4. 
Klapp, O. E. (1986). Overload and boredom: Essays on the quality of life in the information society. Greenwood Publishing Group Inc.

Klausegger, C., Sinkovics, R. R., \& Huan “Joy” Zou. (2007). Information overload: A cross-national investigation of influence factors and effects. Marketing Intelligence \& Planning, 25(7), 691-718. https://doi.org/10.1108/02634500710834179

Lazarus, R. S., \& Folkman, S. (1984). Stress, appraisal, and coping. Springer publishing company.

Lee, A. M., Holton, A., \& Chen, V. (2019). Unpacking overload: Examining the impact of content characteristics and news topics on news overload. Journal of Applied Journalism \& Media Studies, $8(3), 273-290$.

Li, Y., Chandra, Y., \& Kapucu (2020). Crisis coordination and the Role of social media in response to COVID-19 in Wuhan, China. Improving Communication Capacity \& Credibility, 50(6-7), 698-705. https://doi.org/10.1177/0275074020942105

Lopatovska, I. \& Smiley, B. (2014). Proposed model of information behavior in crisis: The case of Hurricane Sandy. Information Research, 19(1). http://informationr.net/ir/19-1/paper610.html

Malhotra, N. K., Jain, A. K., \& Lagakos, S. W. (1982). The information overload controversy: An alternative viewpoint. Journal of Marketing, 46(2), 27-37.

Matthews, J., Karsay, K., Schmuck, D., \& Stevic, A. (2020). "Too much to handle": Impact of mobile social networking sites on information overload, depressive symptoms, and well-being. Computers in Human Behavior, 105.

McMahan, E. A., \& Estes, D. (2011). Measuring lay conceptions of well-being: The beliefs about wellbeing scale. Journal of Happiness Studies, 12, 267-287. doi:10.1007/s10902-010-9194-x

Pang, N. (2014). Crisis-based information seeking: Monitoring versus blunting in the information seeking behavior of working students during the Southeast Asian Haze crisis. Information Research, 19(4). http://informationr.net/ir/19-4/isic/isic14.html

Pentina, I., \& Tarafdar, M. (2014). From "information" to "knowing": Exploring the role of social media in contemporary news consumption. Computers in Human Behavior, 35, 211-223.

Plutchik, R. (1984). Emotions: A general psychoevolutionary theory. In K. R. Scherer \& P. Ekman (Eds.), Approaches to Emotion (pp. 197-218). L. Erlbaum Associates.

Prinz, J. (2005). Are emotions feelings? Journal of Consciousness Studies, 12(8-10), 9-25.

Rachfall, T., Förster-Trallo, D., Williamson, E., \& Temple, B. (2015). The impact of Information Overload on individual stress feelings of management accountants [Conference paper]. International Academic Conference on Management, Economics and Marketing, Budapest.

Ruokolainen, H. \& Widén, G. (2020). Conceptualising misinformation in the context of asylum seekers. Information Processing \& Management, 57(3). https://doi.org/10.1016/j.ipm.2019.102127

Russell, J. A. (1989). Measures of emotion. In R. Plutchik \& H. Kellerman (Eds.), Emotion: Theory, research and experience, Vol. 4. The measurement of emotions (pp. 83-111). Academic Press. 
Savolainen, R. (2007). Filtering and withdrawing: Strategies for coping with information overload in everyday contexts. Journal of Information Science, 33(5), 611-621.

Schmitt, J. B., Debbelt, C. A., \& Schneider, F. M. (2018). Too much information? Predictors of information overload in the context of online news exposure. Information, Communication \& Society, 21(8), 1151-1167.

Schommer, J. C., Doucette, W. R., \& Worley, M. M. (2001). Processing prescription drug information under different conditions of presentation. Patient Education and Counseling, 43(1), 49-59.

Siebenhaar, K. U., Köther, A. K., \& Alpers, G. W. (2020). Dealing with the COVID-19 infodemic: Distress by information, information avoidance, and compliance with preventive measures. Frontiers in Psychology, 11. https://doi.org/10.3389/fpsyg.2020.567905

Song, S., Yao, X., \& Wen, N. (2021). What motivates Chinese consumers to avoid information about the COVID-19 pandemic? The perspective of the stimulus-organism-response model. Information Processing \& Management, 58(1). https://doi.org/10.1016/j.ipm.2020.102407

Soroya, S. H., Farooq, A., Mahmood, K., Isoaho, J., \& Zara, S. E. (2021). From information seeking to information avoidance: Understanding the health information behavior during a global health crisis. Information Processing \& Management, 58(2). https://doi.org/10.1016/j.ipm.2020.102440

Swar, B., Hameed, T., \& Reychav, I. (2017). Information overload, psychological ill-being, and behavioral intention to continue online healthcare information search. Computers in Human Behavior, 70, 416-425. https://doi.org/10.1016/j.chb.2016.12.068

Sweeny, K., Melnyk, D., Miller, W., \& Shepperd, J. A. (2010). Information avoidance: Who, what, when, and why. Review of General Psychology, 14(4), 340-353.

Taylor, T. (2014). Adaptation and the measurement of well-being. Ethics and Social Welfare, 8(3), 248-261. https://doi.org/10.1080/17496535.2014.932417.

Tracy, J., \& Robins, R. (2004). Show your pride evidence for a discrete emotion expression. Psychological Science, 15(3), 194-197. https://doi.org/10.1111/j.0956-7976.2004.01503008.x

Watkins, A. (2015, December 18). Why you feel what you feel [Video file]. YouTube. https://www.youtube.com/watch?v=h-rRgpPbR5w

Wardle, C., \& Dreksham, H. (2017). Information disorder. Council of Europe.

Xie, B., He, D., Mercer, T., Wang, Y., Wu, D., Fleischmann, K. R., ... \& Lee, M. K. (2020). Global health crises are also information crises: A call to action. Journal of the Association for Information Science and Technology, 71(12), 1419-1423.

Yau, N. (2020, March 20). Wheel of emotional words, in case you're having trouble finding the words these days. FlowingData. https://flowingdata.com/2020/03/20/wheel-of-emotional-words/ 


\section{Appendix 1: Survey Questions}

1. Year of birth

2. What is your gender

3. City/Municipality of residence

4. Are you: Student/ Employed/Self-employed/Unemployed/ Homemaker/Retired

5. In which language you seek and get information? : English/Finnish/Swedish

6. Do you belong to a risk group?

7. Have you or someone in your immediate environment been diagnosed with the Coronavirus disease?

8. From where do you get information/news about the corona epidemic at the moment? How do you update yourself about the corona situation? (For example, government health services websites, Yle news on television and/or radio, on websites, newspapers, friends, relatives, social media such as Facebook, Instagram, Youtube, Whatsapp, Snapchat, TikTok etc.)? Why do you choose these sources? People can have a need to receive different kinds of information, and both formal and informal information can be important.

9. Is false/unreliable information about the corona situation a problem for you (for example rumours, misunderstandings, misleading information (disinformation) or contradicting information)? Why is it a problem? How do you evaluate the reliability of the corona information or news?

10. How do you cope with the amount of information/news about the corona situation (too much information, too little information)? What kinds of feelings do you have about the amount of information?

11. Can you give us 1-2 examples of good and 1-2 examples of bad experiences regarding the information about the corona epidemic?

12. Any other experiences you would like to share regarding corona information in general? 
Appendix 2: An overview of respondents' emotions

\begin{tabular}{|c|c|}
\hline Respondents in Finland ( $n=49$ ) & Respondents in the United States $(n=154)$ \\
\hline $\begin{array}{l}\text { Negative Emotions } \\
\text { "Information is too much and I get lost under all the } \\
\text { important information, I am very stressed and anxious } \\
\text { about all this corona-news. It's not important to me to } \\
\text { read every day about how many get sick. It doesn't } \\
\text { change my life and this news could be left out and tell } \\
\text { just those most important things." [Stress and Anxiety] } \\
\text { "There is far too much information. I'm afraid that the } \\
\text { abundance and the } 24 / 7 \text { news report on the epidemic } \\
\text { are causing almost obsessive thinking in humans; if all } \\
\text { you read about is the corona epidemic, then it will be } \\
\text { the only thing that happens in the world. The } \\
\text { information must be more curated and published on a } \\
\text { regular basis - constant news coverage mainly creates } \\
\text { panic." [Fearful] } \\
\text { "Bad feelings. You absolutely need to be updated, but } \\
\text { at the same time I think that if you were to take part in } \\
\text { all the information that is given, at least I would be } \\
\text { crazy. Using the virus as a way to get more readers / } \\
\text { listeners, I think is reprehensible." [Bad] } \\
\text { "There is not too much information, but there is far too } \\
\text { much discussion on the subject. Everyone seems to } \\
\text { need to get their word out on the subject. It's hugely } \\
\text { exhausting, but it's hard to stop following - what if } \\
\text { some important information goes past? The Corona } \\
\text { posts that penetrate every newbie are distressing, } \\
\text { angry and tiring. It feels like there is no room at all for } \\
\text { normal life and everything, just about everything, in } \\
\text { the world and in life is bad." [Anger and Disgust] } \\
\text { Positive Emotions } \\
\text { "There is a lot of information, which is positive." } \\
\text { "I am good at regulating intake and am rarely disturbed } \\
\text { by anything." }\end{array}$ & 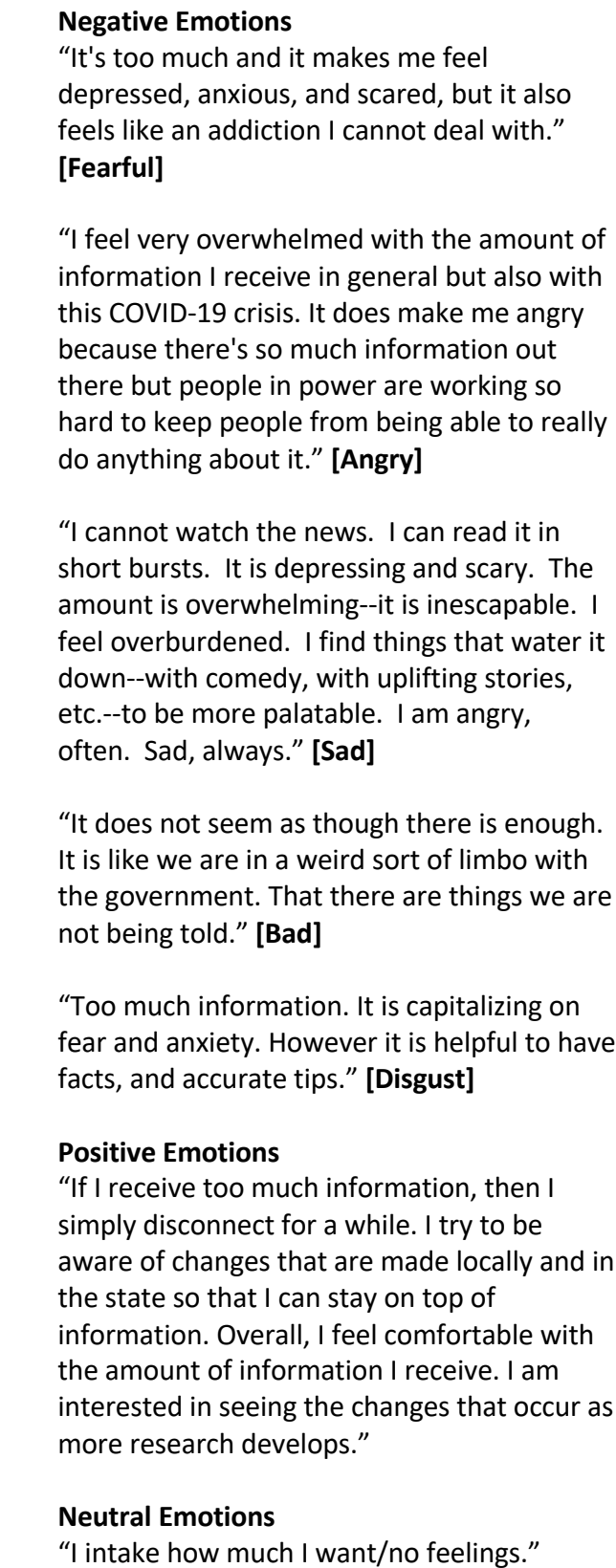 \\
\hline
\end{tabular}


Appendix 3: An overview of respondents' coping mechanisms

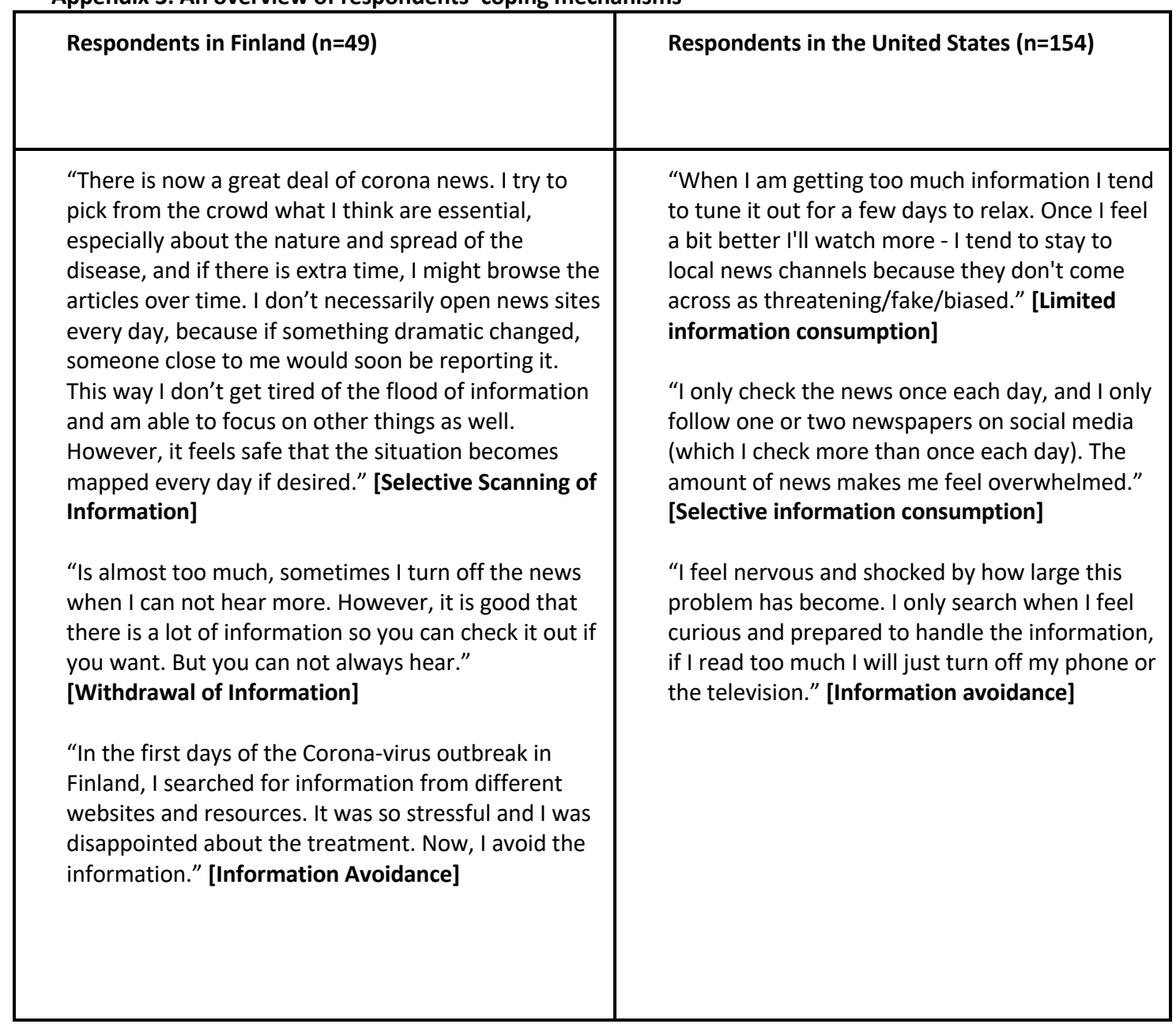


Appendix 4: Respondents' reflections about media and politics

\begin{tabular}{|c|c|}
\hline Respondents in Finland ( $n=-49)$ & Respondents in the United States $(n=154)$ \\
\hline $\begin{array}{l}\text { "A positive experience is the government's } \\
\text { information sessions. These opportunities have } \\
\text { been clear and frequent, and speculation has } \\
\text { remained at a minimum. Ministers have said what } \\
\text { the government has decided, and so it was clear. } \\
\text { Another positive experience is the government's } \\
\text { quest for a cured source of information directly to } \\
\text { the people - earlier in the epidemic, they talked } \\
\text { about a mobile app with corona information, as } \\
\text { well as an information package that would be sent } \\
\text { home to all citizens. I do not know if this will } \\
\text { happen, but the idea is very good - this reduces } \\
\text { the abundance of uncontrolled information, } \\
\text { avoids misinformation and probably reduces the } \\
\text { panic of the population." } \\
\text { "I think the information we have received here in } \\
\text { Finland has been really good and secure. Feels a } \\
\text { little sorry for the Americans." } \\
\text { "US government (Donald Trump) information } \\
\text { opportunities that are only political theater, filled } \\
\text { with misleading information that is only there to } \\
\text { show Trump in a positive light, not to give citizens } \\
\text { information about the virus." }\end{array}$ & $\begin{array}{l}\text { "The everyday press conferences I have started to } \\
\text { ignore. I felt like they did not actually give us any } \\
\text { useful information. Instead I now wait for news on } \\
\text { twitter about what happened in them. Not only do } \\
\text { I feel a lot of the news I get is partisan, I also feel } \\
\text { like it tries to degrade experts in the field. I feel } \\
\text { like I get too much information from national news } \\
\text { sources and not enough information from my local } \\
\text { news or local municipality." } \\
\text { "The biggest problem that makes me cranky right } \\
\text { now is seeing TV opinion people trying to steer } \\
\text { their guests to a particular answer and getting } \\
\text { angry with them when they don't say what they } \\
\text { want them to say. They want these answers to } \\
\text { scare people and get ratings and that sucks quite } \\
\text { frankly. The other big frustration is the language a } \\
\text { lot of people are using - they're using words that } \\
\text { are too vague and allow in uncertainty on what } \\
\text { they actually mean, or words that can allow people } \\
\text { to way too easily misunderstand something." } \\
\text { "I feel like the entire Trump presidency has been } \\
\text { information overload and this pandemic paired } \\
\text { with civil unrest over police brutality has just } \\
\text { exacerbated that feeling. I feel exhausted. I'm on } \\
\text { Twitter all the time in case "something happens" } \\
\text { but I don't know how much I'm accomplishing." }\end{array}$ \\
\hline
\end{tabular}

